Sascha Ruhle, Johannes Siegrist, Stefan Süß, Eva-Ellen Weiß*

\title{
Editorial: Challenging Demands in the Modern Workplace
}

The flexibility of work organization and employment, the growing need for training and development, the digitalization of work, the increasingly blurring boundaries between work and private life-the list of developments that shape the modern working world in recent years is long. Those developments will continue to affect employees as well as organizations and economies. Especially for employees, several of these developments are challenges rather than improvements. Various approaches have increased our understanding of these and similar challenges, including the job demand-control model (Karasek, 1979), leader-member exchange (Graen \& UhlBien, 1995; Hesselgreaves \& Scholarios, 2014), the effort-reward imbalance model (Siegrist, 1996), and the concept of work-family conflict (Barnett, 1998).

As numerous as the challenges resulting from demands in the modern workplace are their potential negative consequences, such as stress experiences (Sparks, Faragher \& Cooper, 2001; Sverke, Hellgren \& Näswall, 2002; Stansfeld \& Candy, 2006; Weiß, 2017) or impairments of individuals' physical and mental health and well-being (e. g. Schnall, Dobson, \& Rosskam, 2009; Siegrist \& Wahrendorf, 2016; Weiß \& Süß, 2017) and job satisfaction. Those consequences can be regarded as threats to organizations because they may result in reduced work engagement and elevated turnover intentions (e. g. Kinnunen, Feldt \& Mäkikangas, 2008; Li, Yang, Cheng, Siegrist, \& Cho, 2005).

Yet, many ways to deal with complex and changing workplace demands are in need of both conceptual and empirical research. To increase our understanding of these complex relationships and to help to answer the challenges resulting from demands in the modern workplace, this special issue includes qualitative and quantitative research from various disciplines, using different approaches to further enhance our understanding of the prevention, occurrence, and the consequences of modern work demands. In the following, we briefly highlight the contributions of this spe-

* Dr. Sascha Ruhle: Chair of Business Administration, in particular Organization Studies and Human Resource Management, Heinrich-Heine University Duesseldorf, Universitätsstraße 1, 40225 Düsseldorf, Germany. E-mail: sascha.ruhle@hhu.de

Prof. Dr. Johannes Siegrist: Senior Professorship 'Work Stress Research', Heinrich-Heine University Duesseldorf, Merowingerplatz 1a, 40225 Düsseldorf, Germany. E-mail: johannes.siegrist@med.uni-duesseldorf.de

Prof. Dr. Stefan Süß: Chair of Business Administration, in particular Organization Studies and Human Resource Management, Heinrich-Heine University Duesseldorf, Universitätsstraße 1, 40225 Düsseldorf, Germany. E-mail: stefan.suess@hhu.de

Dr. Eva-Ellen Weiß: Manchot Graduate School 'Competitiveness of Young Enterprises', Heinrich-Heine University Duesseldorf, Universitätsstraße 1, 40225 Düsseldorf, Germany. E-mail: eva.weiss@hhu.de

mrev, 29 (1) 2018, $1-4$ 
cial issue to our understanding of demands in the modern workplace. This special issue addresses some of the challenges addressed above.

The first contribution by Sebastian Raetze, Silke Geithner, and Gabriele Fassauer analyzes co-configured projects as a specific work setting and how working in such projects not only positively impacts employees but how pathological effects might occur as well. Using a case study design, their study examines how specific demands, stressors, and resources of employees working in co-configured projects create ambivalence. In addition to identifying three types of ambivalence, their study provides evidence for the appropriateness of the Demand-Stressor-Resource Model (Zapf, 1993) within the context of co-configured projects. They describe the complex mechanisms of how work demands can become stressors, but also how stressors can become resources and why resources may become stressors. Finally, they highlight how further research is needed to examine the conditions and situational factors on how and why those changes occur.

Also focusing on the role of specific demands, Karina Becker and Thomas Engel take a look at working conditions and their effects on factors of work-related psychological stress and strains for the temporary workforce. Taking an occupational safety and health perspective, they analyzed data from the BIBB/BAuA employment survey. Using logistic regressions and comparisons between groups of temporary and non-temporary workers, they provide evidence that temporary workers are confronted with weak and inconsistent occupational safety and health conditions. Their results are further evidence for the increased risk of declassing the temporary workforce and for the demanding situations that many of the temporary workers face.

Investigating the consequences of time pressure and psychological climate, the paper from Eva Brosch and Carmen Binnewies emphasizes the role of positive affective states in the formation of work-life conflict and work-life enrichment. Using a fiveday diary study and nested multilevel path models, they show that both relationships are mediated by vigour but not by happiness, adding to the discussion of moods as underlying mechanisms within the work-life interface. Further, and related to the finding that resources can become stressors by Geithner and her colleagues, Brosch and Binnewies find that job control may operate both as a resource and as a demand. Again, this opens avenues for further research regarding boundary conditions for a possible diametrical effect of job resources.

Finally, Susanne Blazejewski and Eva-Maria Walker investigate individual strategies of coping with technological demands. Drawing from the case of a digital merchandise management system, they analyze how individuals engage in job crafting and how this affects stress, which can now-due to changes in technology-occur on a level of negotiating with a technical artefact, such as a digital management system. Enriching literature on job crafting strategies, their results suggest that employees apply diverse cognitive strategies and not only engage in a passive adjustment but in a proactive strategy to deal with the new, digitally framed work situation. 
In addition, this special issue includes three book reviews that encompass different approaches to understanding and explaining demands in the modern workplace and how individuals react to those demands. Ingo Klingenberg reviews 'Work Stress and Coping: Forces of Change and Challenges' by Philip J. Dewe and Cary L. Cooper, who provide an in-depth description of change, stress, and how to deal with it. Corinna Steidelmüller reviews 'Job Demands in a Changing World of Work', a book edited by Christian Korunka and Bettina Kubicek, with several chapters that discuss different pieces of research on job demands and change from various perspectives. Finally, Eva-Ellen Weiß evaluates 'The Handbook of Stress and Health: A Guide to Research and Practice', edited by Cary L. Cooper and James Campbell Quick. The various authors give a comprehensive overview of the most common stress theories and current empirical evidence from stress research concerned with the negative health consequences of stress as well as intervention and prevention approaches.

Yet, we believe that there are still many open questions regarding demands in the modern workplace which should be addressed in further research. This research would benefit from including (additional) individual and organizational consequences that result from the various developments characterizing the modern working world. Also, analyzing circumstances under which particularly problematic work demands arise which may lead to an unequal distribution of burdens among different social or occupational groups would be beneficial for advancing the field further.

Finally, we would like to provide you with some insights into the editorial process of this special issue. We started this project in combination with the 2016 meeting of the German 'Arbeitskreis Empirische Personal- und Organisationsforschung', where some of the authors of this special issue presented early versions of their work. By January 31, 2017, we received 16 contributions of which we selected eleven manuscripts to be included in the review process. From the other five, three manuscripts were desk rejected, and two manuscripts were forwarded to the regular review process of the management revue - Socio-Economic Studies, as they did not fit the scope of the special issue yet convinced us of their quality and potential contribution aside from this special issue. After receiving 22 reviews, we rejected four manuscripts and provided the other seven manuscripts with a chance to revise and resubmit. The authors of four papers followed our invitation to revise and resubmit, and their manuscripts were then again externally reviewed. After another editorial revise, we finally accepted those four manuscripts. Therefore, we would like to thank not only the authors for their contributions but also acknowledge the timely, thoughtful, and constructive support provided by the following reviewers, who greatly helped the authors to improve their manuscripts:

Peter Angerer; Magret Borchert; Kai Bormann; Heiko Breitsohl; Mathias Diebig; Isabelle Dorenkamp; Nico Dragano; Sven Hauff; Christina Hoon; Heiko Hossfeld; 
Rodrigo Isidor; Stephan Kaiser; Georg Loscher; Albert Martin; Wolfgang Mayrhofer; Andreas Müller; Renate Ortlieb; Hans-Gerd Ridder; Martin Schneider; Christian Schwens; Rick Vogel; Marius Wehner.

\section{References}

Barnett, R. C. (1998). Toward a review and reconceptualization of the work/family literature. Genetic Social and General Psychology Monographs, 124(2), 125-182.

Graen, G.B., \& Uhl-Bien, M. (1995). Relationship-based approach to leadership: Development of leader-member exchange (LMX) theory of leadership over 25 years: Applying a multi-level multi-domain perspective. The Leadership Quarterly, 6(2), 219-247.

Hesselgreaves, H., \& Scholarios, D. (2014). Leader-member exchange and strain: a study of job demands and role status. Human Resource Management Journal, 24(4), 459-478.

Karasek, R. A. (1979). Job demands, job decision latitude and mental strain: implications for job redesign. Administrative Science Quarterly, 24(2), 285-308.

Kinnunen, U., Feldt, T., \& Mäkikangas, A. (2008). Testing the effort-reward imbalance model among Finnish managers: The role of perceived organizational support. Journal of Occupational Health Psychology, 13(2), 114-127.

Li, J., Yang, W., Cheng, Y., Siegrist, J., \& Cho, S. (2005). Effort-reward imbalance at work and job dissatisfaction in Chinese healthcare workers: a validation study. International Archives of Occupational and Environmental Health, 78(3), 198-204.

Schnall, P., Dobson, M., \& Rosskam, E. (Eds.) (2009). Unhealthy work: Causes, consequences, cures. New York: Baywood.

Siegrist, J. (1996). Adverse health effects of high-effort/low-reward conditions. Journal of Occupational Health Psychology, 1(1), 27-41.

Siegrist, J., \& Wahrendorf, M. (2016). Work stress and health in a globalized economy. Cham: Springer Verlag.

Sparks, K., Faragher, B., \& Cooper, C. L. (2001). Well-being and occupational health in the 21 stcentury workplace. Journal of Occupational and Organizational Psychology, 74(4), 489-509.

Stansfeld, S., \& Candy, B. (2006). Psychosocial work environment and mental health - a metaanalytic review. Scandinavian Journal of Work, Environment \& Health, 32(6), 443-462.

Sverke, M., Hellgren, J., \& Näswall, K. (2002). No security: a meta-analysis and review of job insecurity and its consequences. Journal of Occupational Health Psychology, 7(3), 242-264.

Weiß, E. (2017). Worktime control and work stress: The moderating effect of self-comparisons and social comparisons. The International Journal of Human Resource Management, online first, DOI: $10.1080 / 09585192.2017 .1365747$.

Weiß, E., \& Süß, S. (2017). Protective faith? The role of religiosity in the stressor-strain relationship in helping professions. The International Journal of Human Resource Management, online first, DOI: 10.1080/09585192.2017.132538.

Zapf, D. (1993). Stress-oriented analysis of computerized office work. European Work and Organizational Psychologist, 3(1), 85-100. 